\title{
A message from the Patron
}

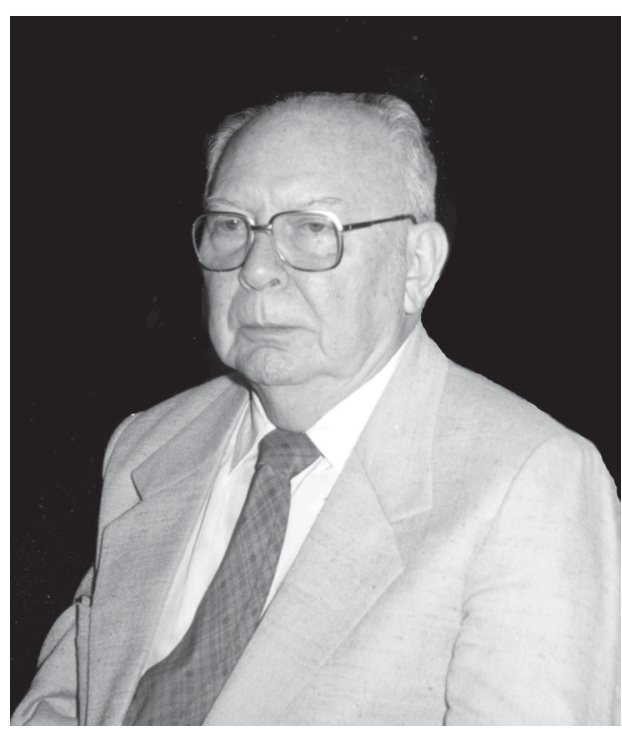

W Lobato Paraense - Patron of the 10th International Symposium on Schistosomiasis
Upon arriving at the Oswaldo Cruz Institute, I joined the team of Evandro Chagas, who was engaged in studies on kala azar (visceral leishmaniasis), recently verified in the country, which became the main subject of my first publications at the Institute. In the following year I was assigned to lecture Pathology in a course on malaria. I became so interested in the subject that I started investigating the so called "exoerythrocytic cycle" of Plasmodium, and published several articles, among which one that revealed the initial stages of the parasite before entering the red cells, recognized as a pioneer work by the eminent protozoologist CM Wenyon. Afterwards I returned to the studies on Leishmania, investigating the dissemination mechanism of the newly discovered $L$. enriettii into the organism of the natural host, the guinea pig.

Meanwhile I had been working in Belo Horizonte, where schistosomiasis occurs, and then I decided to verify the identity of the local vector, regarded by Lutz as being his Planorbis centimetralis (now Biomphalaria straminea), whose shell diameter, according to that investigator, "is about $1 \mathrm{~cm}$., varying $1 \mathrm{~mm}$., to more or less". After examining a large number of samples collected in breeding places throughout the city, four sites were selected to be observed once a month for one year, including the only one referred to by Lutz. A biometric analysis of the samples revealed the absence of any centimetralis population. Dissections showed that, excepting a single specimen $10 \mathrm{~mm}$ in shell diameter, Schistosoma mansoni infection occurred exclusively in specimens 12 to $30 \mathrm{~mm}$, now known as Biomphalaria glabrata.

Also by mere curiosity I collected planorbids, from April 1953 to April 1954, at Lagoa Santa, a lake situated in a homonymous town in the state of Minas Gerais, where the famous naturalist Peter W Lund lived and worked. There I easily found specimens of B. glabrata infected with S. mansoni, a fact that shocked the population of Belo Horizonte, because the lake is surrounded by a large residential area and country villas of wealthy people, who used the lake for swimming, including competitions at national and international levels.

Those observations induced some influential figure of the Serviço Especial de Saúde Pública (Sesp) to suggest my name to participate in the investigations on molluscs in areas of occurrence of schistosomiasis under its jurisdiction, mainly in the states of Minas Gerais and Espírito Santo, and in some Northeastern states. As then I had no interest in systematics, considering it a mere enumeration of morphological features, I refused two invitations to work in Sesp.

At that time I used to go to Rio de Janeiro for a monthly meeting of the National Research Council (CNPq), availing myself of the opportunity to update my knowledge at the library of the Oswaldo Cruz Institute and, on the way back to the airport, to visit a scientific bookstore. In November 1954 a book attracted my attention: The New Systematics, edited by Julian Huxley, including 22 chapters on various aspects - genetic, geographical, ecological, embryological, evolutionary, paleontological - of animal and vegetal taxonomy, besides one entitled Taxonomy and Philosophy. Several days later I could not refuse a third invitation of Sesp and became involved in malacological taxonomy. Now, 50 years passed working in the area and 90 years old, I do not repent of that decision.

Finally, I would like to thank my dear colleague Omar dos Santos Carvalho for proposing my name for Patron of the X Symposium on Schistosomiasis, and my colleagues present at the "10th Meeting of the Schistosomiasis Researchers of Fiocruz", held in Teresópolis, for accepting such proposal, what touches and honors me.

W Lobato Paraense 
